\title{
Student Perspective on a Predoctoral Interprofessional Education Initiative
}

\author{
Shibani Sahni ${ }^{1, *} \&$ Sang Park ${ }^{2}$ \\ ${ }^{1}$ Lecturer in Oral Health Policy and Epidemiology, Harvard School of Dental Medicine, Boston, MA, USA \\ ${ }^{2}$ Associate Dean for Dental Education, Harvard School of Dental Medicine, Boston, MA, USA \\ *Harvard School of Dental Medicine, 188 Longwood Avenue, Boston, MA 02115, USA. E-mail: \\ shibani_sahni@hsdm.harvard.edu
}

Received: October 4, 2021

Accepted: November 30, $2021 \quad$ Online Published: January 18, 2022

doi: $10.5430 /$ jct.v11n2p29

URL: https://doi.org/10.5430/jct.v11n2p29

\begin{abstract}
Objective- The purpose of this study was to investigate students' perspectives on a newly implemented program of Interprofessional education (IPE) in terms of its effectiveness in increasing the awareness about other health care professionals and providing tools to emerging dental professionals for comprehensive health care needs.

Methods- A new IPE course was incorporated in the second year of the predoctoral dental curriculum, and educators and students from various health professionals came together to provide a collaborative learning environment. The study evaluated the survey data from the graduating classes of 2019 and 2020 in the predoctoral program at Harvard School of Dental Medicine. The students were surveyed during and at the end of the course to obtain their perspectives on the effectiveness of the program.

Result-The results of the surveys showed most student respondents agreed strongly that they liked getting information from other health professionals and 93-95\% agreed that collaborating with other members of the health care team can help facilitate patients' overall health care. The IPE sessions helped bring about awareness of interprofessional relations and communications within the health care team and prepared the students for holistic patient care.

Conclusion- The IPE methods facilitated an interactive and interprofessional learning environment to assist students in developing awareness of interprofessional relations and communications within the health care team. The connections between oral and systemic health were reinforced, thus giving predoctoral dental students a wider view of patient treatment and consideration for their patients' comprehensive health care needs.
\end{abstract}

Keywords: IPE, Interprofessional education, Education methodology, comprehensive care, predoctoral dental education

\section{Introduction}

Interprofessional Education (IPE) involves providing patient centered care along with patient safety by working within and across health care. There have been various challenges in implementing IPE within the dental curriculum. (Davis, Janczukowicz, Stewart, Quinn, \& Feldman, 2018; Park, Salihoglu-Yener, \& Fazio, 2019; Park \& Howell, 2015; Andrews, 2017; Park, Donoff, \& Saldana, 2017; Peeters, Sexton, Metz, \& Hasbrouck, 2017; Interprofessional Professionalism Collaborators, 2016; Canadian Interprofessional Health Collaborative, 2010; Jones, Snyder, Gesko, \& Helgeson, 2017; Hendricson \& Cohen, 2001) The growing demand for providing comprehensive patient care has required dental education to embrace new approaches and methodologies for preparing dental students and an important goal is to prepare future health professionals for team-based care of patients. (Davis et al, 2018; Park, Salihoglu-Yener, \& Fazio, 2019)

Interprofessional health care teams are necessary to provide improved health care outcomes for patients and to address complex medical needs. The goal is for dentists to be able to work in collaboration with other health care fields such as public health, pharmacy, psychology, physiotherapy, medicine, nursing, and osteopathic medicine, and to have shared values and goals for promoting quality health care. (Davis et al., 2018; Park, Salihoglu-Yener, \& Fazio, 2019; Park \& Howell, 2015) Creating a shared taxonomy amongst health care professions broadens interprofessional competencies 
to improve patient care and the health of the population. Therefore, future health care providers need training in such collaborative teams to facilitate communication and professionalism, and thus improve patient outcomes. (Andrews, 2017; Park, Donoff, \& Saldana, 2017) It is essential that dental curricula prepare students to work in interprofessional teams and to provide collaborative care for patients. (Park, Donoff, \& Saldana, 2017; Peeters et al., 2017; Interprofessional Professionalism Collaborators, 2016; Canadian Interprofessional Health Collaborative, 2010; Jone et al., 2017; Hendricson \& Cohen, 2001)

At Harvard School of Dental Medicine (HSDM), a new interprofessional education (IPE) course was introduced for the predoctoral students in the second year. An integrated clinical rotation was offered to train students to meet the comprehensive treatment needs of the general population. (Park, Donoff, \& Saldana, 2017) The integrated clinic aimed to engage students from different professions for interactive learning with each other and to teach students primary care medicine with a focus on oral health. In this model, students from different disciplines of health care learned from each other in sessions facilitated and guided by faculty from across the health care professions.

The IPE sessions were designed to deepen students' understanding of the connection between oral and systemic health, thus giving predoctoral dental students tools for comprehensive health care needs of the patients and giving students from other health care professions a sense of the importance of oral health to general patient health. The purpose of the study was to assess effectiveness in student learning as measured by student satisfaction and increased awareness about other health care professionals upon implementation of an IPE course in the predoctoral program.

\section{Methods and Materials}

The study was reviewed and approved by the Institutional Review Board at HSDM (IRB16-1234). Interprofessional education sessions consisted of four monthly two-hour sessions for the second-year dental students of HSDM. Efforts were made to engage students from non-dental health care professions to facilitate interactive learning and to teach students primary care medicine with a focus on oral health. Faculty from different professions including dentists, physicians, nurse practitioners, pharmacists and behavioral psychiatrists facilitated and guided these sessions to intensify student understanding of the oral and systemic connection and to give the predoctoral students tools to consider a patient's comprehensive health care needs.

Team based learning (TBL) was implemented in the IPE sessions. The sessions started with an individual ten question multiple choice quiz involving general information about the health condition on which the session would be focused, followed by the same quiz taken by groups of eight students. (Park, Salihoglu-Yener, \& Fazio, 2019) A clinical case with both dental and medical considerations was presented to the students and discussed by the student groups, allowing them to apply interdisciplinary knowledge and critical thinking skills. Students participating in IPE sessions were asked to complete surveys about their experiences and learning, and the effectiveness of the session in preparing students to enter a collaborative workforce. Learning skills were measured with survey questions using a 5-point Likert response scale from Strongly Agree to Strongly Disagree. The surveys were administered on paper at the end of each IPE session. At the end of the course, students were asked general questions about which style of learning they preferred and whether the sessions had helped them understand the cases from the perspective of other health care professionals.

\section{Results}

In the class of $2019,92-95 \%$ of student respondents agreed strongly across the first three sessions that they liked getting information from other health professionals. The numbers were similar for the class of 2020. 93-95\% agreed across the first three sessions in the class of 2019 that collaborating with other members of the health care team can help facilitate patients' overall health care and again the numbers in the class of 2020 were similar. About $85-95 \%$ agreed, across the two years, that they would like to have opportunities to learn with other health care students as a part of their training. (Table 1).

Upon being surveyed with a free text question as to which additional health professionals the students would like to see invited to participate in the sessions, a majority stated nutritionist, followed in popularity by physical therapist, nurse practitioner, pharmacist, dental hygienist, primary care doctor, ENT specialist, social worker, and speech therapist.

At the end of the course each year, students were surveyed on whether the sessions had helped the students understand the cases from the perspective of other health care professionals. Roughly $76 \%$ of the class of 2019 either agreed or strongly agreed, and about $62 \%$ of the class of 2020 agreed or strongly agreed. When asked if the sessions had helped the students understand the links between oral health and general health, $73 \%$ of the class of 2019 either strongly 
agreed or agreed and $78 \%$ of the class of 2020 either agreed or strongly agreed (Table 1). Most students had benefited from these sessions; $70 \%$ of the class of 2019 and $51 \%$ of the class of 2020 had agreed or strongly agreed that these sessions had increased the knowledge of interprofessional relations and communication within a health care team.

Table 1. Usefulness of IPE to Dental Students for Classes of 2019 and 2020

\begin{tabular}{lll}
\hline Question & Category & Average \\
\hline I liked getting information from other health & Strongly agree & $45 \%$ \\
professionals. & Somewhat agree & $46 \%$ \\
& Neutral & $6.5 \%$ \\
& Somewhat disagree & $1.5 \%$ \\
& Strongly disagree & $1 \%$ \\
I believe that collaborating with other members of the & Strongly agree & $63.5 \%$ \\
health care team can help facilitate patients' overall & Somewhat agree & $29 \%$ \\
health care. & Neutral & $6 \%$ \\
& Strongly disagree & $1 \%$ \\
& Somewhat disagree & $1 \%$ \\
I would like to have opportunities to learn with other & Strongly agree & \\
health care students as part of my training. & Somewhat agree & $90 \%$ \\
& Neutral & $0 \%$ \\
& Strongly disagree & $1 \%$ \\
& Somewhat disagree & $0 \%$ \\
& & $9 \%$ \\
\hline
\end{tabular}

Working in the same groups during IPE helped build rapport among the small groups. It was also suggested that team-based learning (TBL) lead to better communication skills, critical thinking skills and peer -to -peer learning. TBL has helped in a higher retention and application of knowledge. The results suggested that across the two years, $24 \%$ students liked lecture-based, $71 \%$ preferred team-based and only $5.5 \%$ thought flipped classroom helped with knowledge acquisition (Table 2).

Table 2. Students' Preferred Style of Learning for IPE Sessions

\begin{tabular}{lll}
\hline Question & Category & Average \\
\hline Which style of learning do you prefer for IPE? & Lecture & $24 \%$ \\
& Team-Based & $70.5 \%$ \\
& Flipped & $5.5 \%$ \\
\hline
\end{tabular}

Every year, the graduating DMD class at HSDM is given a survey of their overall educational experience with specific questions about didactic and clinical courses and general questions about pedagogies (e.g., TBL, flipped classrooms) and areas of focus (e.g., emphasis on connections between oral and systemic health, IPE). The class of 2019 experienced the pilot year of the IPE sessions in 2016-2017, and the graduation survey found that $23 \%$ had found them very helpful, $26 \%$ somewhat helpful and $52 \%$ did not find it helpful. (Table 3 )

The students also were asked if they felt prepared in collaborating with other health professionals like hygienists, dental assistants, lab technicians, etc. and $90 \%$ suggested that they were either prepared, well prepared or very well prepared. When asked the question about how well the felt in their preparation towards collaborating with other health care professionals like primary care doctors, medical specialists like cardiologists, pharmacists etc., about $87 \%$ reported to be either prepared, well prepared or very well prepared. (Table 3)

The class of 2020, which had had IPE sessions in 2017-2018, reported in the graduation survey that $13 \%$ agreed that IPE was very helpful, $27 \%$ found it somewhat helpful and $60 \%$ did not find it helpful. They were also asked if they felt prepared in collaborating with other health professionals like hygienists, dental assistants and $97 \%$ felt that they were prepared, well prepared or very well prepared. Upon asking how well prepared they felt to collaborate with other health 
care professionals like primary care doctors, medical specialists (e.g., cardiologists, pharmacists, etc.), a similar percentage of $97 \%$ reported that they felt prepared, well prepared or very well prepared.

Table 3. Students' Perception at Graduation as to Helpfulness of IPE Sessions and Preparedness to Collaborate with Dental and Other Health Care Professionals

\begin{tabular}{lll}
\hline Category & Average & \\
\hline Very helpful & $13 \%$ & \\
Somewhat helpful & $27 \%$ & \\
Not helpful & $60 \%$ & Average: Other \\
& & $26 \%$ \\
Category & Average: Dental & $36.5 \%$ \\
Very well prepared & $33 \%$ & $26.5 \%$ \\
Well prepared & $39.5 \%$ & $8 \%$ \\
Prepared & $21.5 \%$ & 0 \\
Somewhat unprepared & $6.5 \%$ & \\
Very unprepared & 0 & \\
\hline
\end{tabular}

During the pilot year of the IPE course, many students thought that going over the group quiz answers took up too much time and did not allow for enough time to discuss the actual cases. Based on this feedback, we modified the quizzes from general knowledge questions to case based. The health conditions discussed in the sessions were also modified, based on a course survey question that had asked what conditions students would like to discuss; asthma and pregnancy were the most requested. In addition, we asked medical faculty with expertise in the particular conditions the cases discuss to review them and consult with us on making them more robust for discussion. Students were also asked how many cases should be discussed in a session, as some students thought that taking the whole session for a single case was not productive use of time.

The study was limited by the small number of IPE sessions presented per year, and by the small number of non-dental health care fields available for collaboration in the early years of the program. The program's progress since its introduction, and the adoption of interprofessional education requirements in a larger number of health care fields, have led to broader interest from non-dental health care professions. Future studies could include greater participation by students in health care professions outside of dentistry.

\section{Discussion}

Interprofessional education (IPE) is an important component of health care education and training for future health care professionals. (Donoff \& Daley, 2020; Cohen, 2013; Freukel \& Laurie, 2002; Barr, Koppel, Reeves, Hammick, \& Freeth, 2005) The training for health care professionals should focus on being patient-centered and health care professionals should be able to collaborate across health care fields which will benefit the patient's overall health. (Brashers, Curry, Harper, et al., 2001; Freeth, Hammick, Reeves, Koppel, \& Barr, 2005; TeamStepps, 2009; Institute of Medicine Committee on the Health Professions Education Summit, 2003; World Health Organization, 1988; Burin, Bhushan, Broeseker, Conway, Duncan-Hewitt, Hansen, \& Westberg, 2009) Inclusion of IPE in the health care curriculum would help students maintain shared values and respect across professions as students will be trained to use the knowledge of their own role and those of other professions. Through this collaborative effort, patients' health care needs are addressed in comprehensively, and thereby promoting and advancing the health of populations. (Donoff \& Daley, 2020; Freeth et al., 2005; Interprofessional Education Collaborative, 2020)

Experiential interprofessional collaboration is an important component of IPE which is required in dental education. (Peeters et al., 2017; Cohen, 2013) The institute of Medicine declared that "health professionals should be educated to deliver patient-centered care as members of an interdisciplinary team. (Institute of Medicine Committee on the Health Professions Education Summit, 2018) The aim for teaching IPE to the students is for them to learn how be a part of an interprofessional team and be able to carry this knowledge and skills into their future practice, ultimately providing interprofessional patient care as a part of collaborative team. (Freukel \& Lurie, 2002; Barr et al., 2005; Buring et al., 2009) Comprehensive patient care is paramount and it is easier to understand the links when we are treating the patient holistically. However, a significant challenge lay in attempting to organize interprofessional sessions in the first place, 
given that health care curricula in all fields are tightly scheduled as we attempt to implement something new.

TBL structure was used for the IPE course in the current study in which students had an opportunity to work as a group. Student feedback had shown a strong preference for TBL over the traditional lecture format. The TBL method contributed to facilitating an interactive learning environment to promote student-centered learning in a predoctoral education course and the teams performed better in correct evaluation compared with individual students. (Park, Salihoglu-Yener, \& Fazio, 2019) Working with the groups also enabled to develop rapport and collaboration among the group and the students developed interprofessional skills and engaged in more thoughtful discussions resulting in better learning.

The final course surveys in the current study demonstrated that the IPE sessions helped students understand the perspective of other health care professionals and raised their awareness of the links between oral health and general health. These sessions also made the students aware of the importance and usefulness of interprofessional relations and communication with a health care team. An analysis of the survey results from the pilot year revealed that students had derived considerable benefit from the IPE sessions and had requested more professionals from diverse fields. Additional patient cases were incorporated upon analyzing the survey following the pilot year to include efforts across the different professions and the active interaction between them contributed to student learning, collaboration, critical thinking and satisfactory feedback.

The broader implication of the results is that the majority of students saw value in interprofessional education. These sessions were also critical for the non-dental professions, as they conveyed a sense of the importance of oral health to general patient health. For instance, the pharmacy students were able to understand the implications of different medications on oral health and the drug interaction with various treatment procedures. IPE sessions prepared students to encounter a collaborative learning environment and contributed to their understanding of roles and responsibilities within an interprofessional health care team. Moving forward, training for faculty, residents and clinicians will be important for adoption and promotion of IPE.

In the future, the skills needed by dental professionals will include communication and collaboration with other health care professionals. In a health care delivery system moving towards more patient centered, team-based care, interprofessional education will be beneficial to help future clinicians develop into confident team members who will produce better patient outcomes through competency-based dental education and patient-centered health care education. (Andrews, 2017; Interprofessional Education Collaborative, 2020) Further research may be necessary on the potential of interprofessional shared health care records for their benefits from all-inclusive electronic health care records, which can contribute to creating a model where IPE can be practically delivered to the patient-centered comprehensive care.

The study was limited by the small sample size of 35 students inherent to the class size and the small number of IPE sessions presented per year, and by the small number of non-dental health care fields available for collaboration in the early years of the program. The program's review since its introduction, and the adoption of interprofessional education requirements in a larger number of health care fields, have led to broader interest from non-dental health care professions. Future studies could include greater participation by students in health care professions outside of dentistry.

\section{Conclusion}

The IPE method contributed to the understanding of roles and responsibilities within an interprofessional health care team and facilitated increased awareness about the connections between oral and systemic health and other health care professionals. It has offered predoctoral dental students a wider view of awareness of interprofessional relations and communications within the health care team.

\section{References}

Andrews, E. A. (2017). The Future of Interprofessional Education and Practice for Dentists and Dental Education. $J$ Dent Educ., 81(8), eS186-eS192. https://doi.org/10.21815/JDE.017.026

Barr H., Koppel I., Reeves S., Hammick M., \& Freeth D. (2005). Effective Interprofessional Education: Argument, Assumption \& Evidence. Oxford, UK: Blackwell.

Brashers V. L., Curry C. E., \& Harper D. C., et al. (2001) Interprofessional health care education: recommendations of the National Academies of Practice expert panel on health care in the 21st century. Issues in Interdisciplinary Care: National Academies of Practice Forum, 3(1), 21-31. 
Buring, S. M., Bhushan, A., Broeseker, A., Conway, S., Duncan-Hewitt, W., Hansen, L., \& Westberg, S. (2009). Interprofessional education: definitions, student competencies, and guidelines for implementation. American journal of pharmaceutical education, 73(4), 59. https://doi.org/10.5688/aj730459

Canadian Interprofessional Health Collaborative. (2010). A national interprofessional competency framework. Retrieved from www.cihc.ca/resources/publications

Cohen L. A. (2013) Expanding the physician's role in addressing the oral health of adults. Am J Public Health, 103(3), 408-412. https://doi.org/10.2105/AJPH.2012.300990

Davis, J. M., Janczukowicz, J., Stewart, J., Quinn, B., \& Feldman, C. A. (2018). Interprofessional education in dental education: An international perspective. Eur J Dent Educ., 22(Suppl 1), 10-16. https://doi.org/10.1111/eje.12341

Donoff R. B., \& Daley G. Q. (2020). Oral health care in the 21st century: It is time for the integration of dental and medical education. J Dent Educ., 84(9), 999-1002.

Freeth D., Hammick M., Reeves S., Koppel I., \& Barr H. (2005). Effective Interprofessional Education: Development, Delivery \& Evaluation. Oxford, UK: Blackwell.

Freukel D. A., \& Lurie Y. (2002). Responsibility and liability in health care: some differences between dentistry and medicine. Med Law., 21(3), 605-615.

Hendricson, W. D., \& Cohen, P. A. (2001). Oral health care in the 21st century: implications for dental and medical education. Acad Med., 76(12), 1181-1206. https://doi.org/10.1097/00001888-200112000-0000

Institute of Medicine Committee on the Health Professions Education Summit. Health Professions Education. (2003). A Bridge to Quality. In: Greiner AC, Knebel E., (Eds.). Washington, DC: National Academy Press

Interprofessional Education Collaborative. Core competencies for interprofessional collaborative practice: 2016 update. (2020) Washington, DC: Interprofessional Education Collaborative. Retrieved November 23, 2020 from https://www.ipecollaborative.org/core-competencies.html

Interprofessional Professionalism Collaborators. (2016). Interprofessional Professionalism Behaviors. Alexandria, VA: Interprofessional Professionalism Collaborative. Retrieved from http://www.interprofessionalprofessionalism.org/

Jones, J. A., Snyder, J. J., Gesko, D. S., \& Helgeson, M. J. (2017). Integrated Medical-Dental Delivery Systems: Models in a Changing Environment and Their Implications for Dental Education. J Dent Educ., 81(9), eS21-eS29. https://doi.org/10.21815/JDE.017.029

Park, S. E., Donoff, R. B., \& Saldana, F. (2017). The Impact of Integrating Oral Health Education into a Medical Curriculum. Med Princ Pract., 26(1), 61-65. https://doi.org/10.1159/000452275

Park, S. E., \& Howell, T. H. (2015). Implementation of a flipped classroom education model in a predoctoral dental course. J Dent Educ., 79(5), 563-70.

Park, S. E., Salihoglu-Yener, E., \& Fazio, S. B. (2019). Use of team-based learning pedagogy for predoctoral teaching and learning. Eur J Dent Educ., 23(1), e32-e36. https://doi.org/10.1111/eje.12396

Peeters, M. J., Sexton, M., Metz, A. E., \& Hasbrouck, C. S. (2017). A team-based interprofessional education course for first-year health professions students. Curr Pharm Teach Learn., 9(6), 1099-1110. https://doi.org/10.1016/j.cptl.2017.07.006

TeamStepps. (2009). Strategies and Tools to Enhance Performance and Patient Safety, Agency for Healthcare Research and Quality, U.S. Department of Health and Human Services. Retrieved April 17, 2021 from http://teamstepps.ahrq.gov/index.htm

World Health Organization. Vol. 769. Geneva: World Health Organization. (1988). Learning Together to Work Together for Health. Report of a WHO study group on multiprofessional education for health personnel: the team approach. Technical Report Series; pp. 1-72.

\section{Copyrights}

Copyright for this article is retained by the author(s), with first publication rights granted to the journal.

This is an open-access article distributed under the terms and conditions of the Creative Commons Attribution license (http://creativecommons.org/licenses/by/4.0/). 